\title{
Research of An Undergraduate Innovation and Entrepreneurship Training Program
}

\author{
Zhihong $\mathrm{Xiao}^{\mathrm{a}^{*}}$ and Zuo Wei ${ }^{\mathrm{b}}$ \\ School of Electronic Engineering, Xi'an Shiyou University, Xi'an, China

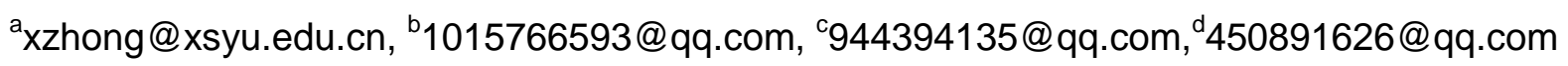 \\ e1440285852@qq.com
}

\begin{abstract}
Keywords: Undergraduate Innovation and Entrepreneurship Training Program; Storage industry; Temperature; Humidity; Control
\end{abstract}

\begin{abstract}
The undergraduate innovation and entrepreneurship training program is set up by educational authorities for undergraduates. This paper introduces the research situation of undergraduate innovation and entrepreneurship training program " design of automatic control system of temperature and humidity for storage". Aiming at the current situation of environmental control in storage industry, an automatic control system of temperature and humidity for storage is designed by project team members. The system consists of temperature and humidity measurement circuit, temperature and humidity control circuit, the keyboard, the display circuit and the communication interface, etc. It can detect and control actual temperature and humidity, which uses STC90C516 as the control center, using SHT15 as the sensor. With the help of keyboard, consumer can set the required value and the upper and lower alarm of temperature and humidity online, and achieve the data remote transmission. The actual results show the temperature accuracy could be controlled within $\pm 1{ }^{\circ} \mathrm{C}$ and humidity accuracy could be controlled within $\pm 4 \%$. Through the exercise of the project, students learned how to use their knowledge to solve problems in practice, their innovative ability and cooperation spirit were also improved.
\end{abstract}

\section{Introduction}

The Undergraduate Innovation and Entrepreneurship Training Program. The Program is an important part of the Undergraduate Teaching Quality and Teaching Reform Project setting by educational authorities[1]. The innovative training program is for an individual or a team, under the guidance of professors, complete innovative research project design, preparation and implementation of the project study conditions, the researchers report writing, the results of (academic) exchanges and so on autonomously. It is aimed to transform the concept of talent cultivation, promote college students innovative quality and ability to increase reserve talents for the country[2-7].

The information of the project "design of automatic control system of temperature and humidity for storage". Storage is a place for storing materials, widely used in the textile industry, forestry, chemicals, agriculture, construction sites and the military-industrial complex and other areas. There are a large number of different types of materials warehouse, located in different climatic zones. Some factors affect the quality of many goods store, but the greatest impact is the air temperature and humidity. Studying materials storage temperature and humidity conditions is an important part of the quality assurance of materials, it has a direct impact on the life and work stockpile reliability. Therefore, environmental temperature, humidity must be controlled until the temperature and humidity are within the scope of reach standard[8-13]. 


\section{The composition of the system}

The system is consists of microcontroller, temperature and humidity measurement circuit, keyboard circuit, clock circuit, display circuit and communication interface. The hardware block diagram of the system is shown in Figure1.

STC90C516 is a low-power, high-performance CMOS 8-bit microcontroller with 64KB of flash memory. The device uses Atmel high-density, nonvolatile memory technology and is compatible with the industry-standard 80C51 instruction set and pinout. On-chip flash allows program memory to be reprogrammed in-system or by a conventional nonvolatile memory programmer.

The temperature and humidity measurement circuit adopts censor SHT15, which enjoys a high level of linearity and the accuracy won't change as the length of wire. Its measuring resolution is 14 bit (temperature) and 12 bit (humidity).

The keyboard circuit's function is to determine the working state of the system and set parameters. There are two kinds of working state of the circuit, one kind is set condition, and the other one is running state. In the set condition we can set plan production and correct the current time parameters by keyboard. The needed value and upper and lower limit of alarm of temperature and humidity can be set up online.

There is dithering elimination circuit composed of resistance-capacitance circuit, which is used to relieve interference of key dithering. One of the keyboard circuit is shown in Figure2.

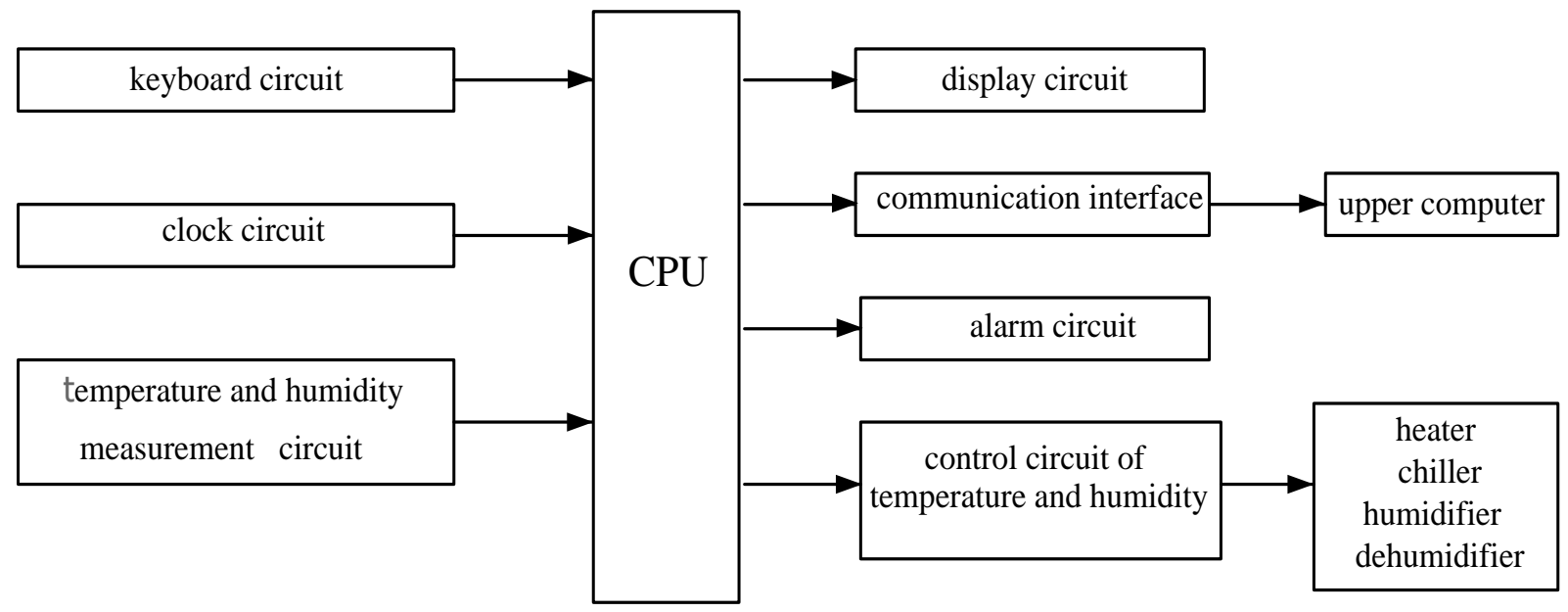

Figure. 1 The hardware block diagram of the system

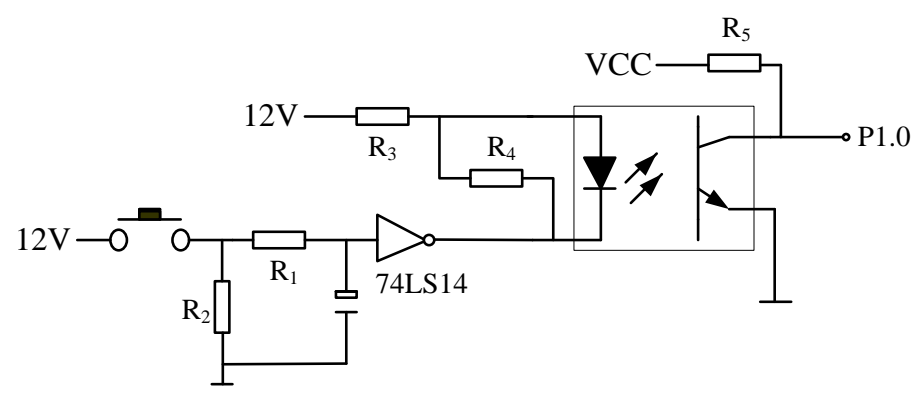

Figure. 2 One of the keyboard circuit

The upper and lower limit value of temperature and humidity are inputted through the keyboard, When the measured value exceed the limit value, the alarm lights and the actuator action at the same time, until the temperature and humidity are within the scope of reach standard. The actuator is 
consists of heater, chiller, dehumidifier and humidifier.The control circuit of heater is shown in Figure3.

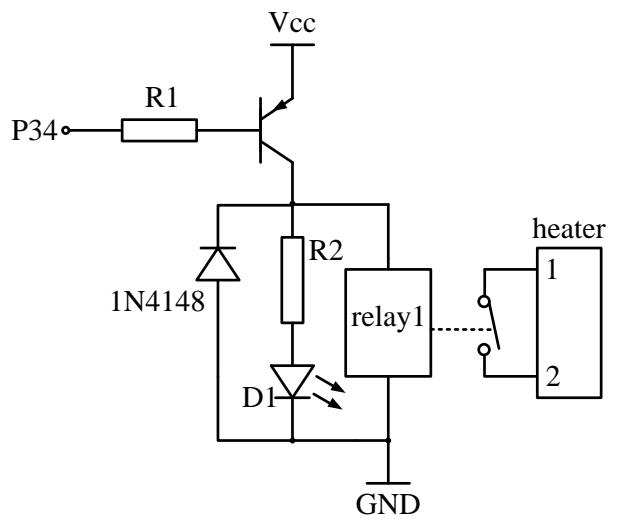

Figure. 3 Control circuit of heater

\section{System Software Design}

The system software is designed modularly and consists of temperature and humidity testing program, temperature and humidity control program, key handler, interrupt execution program, LCD display program, timing program and serial communication program, etc. The main program completes the initialization of the device and calls the appropriate subroutine modules according to the system requirements. The main program block diagram is shown in Figure4.

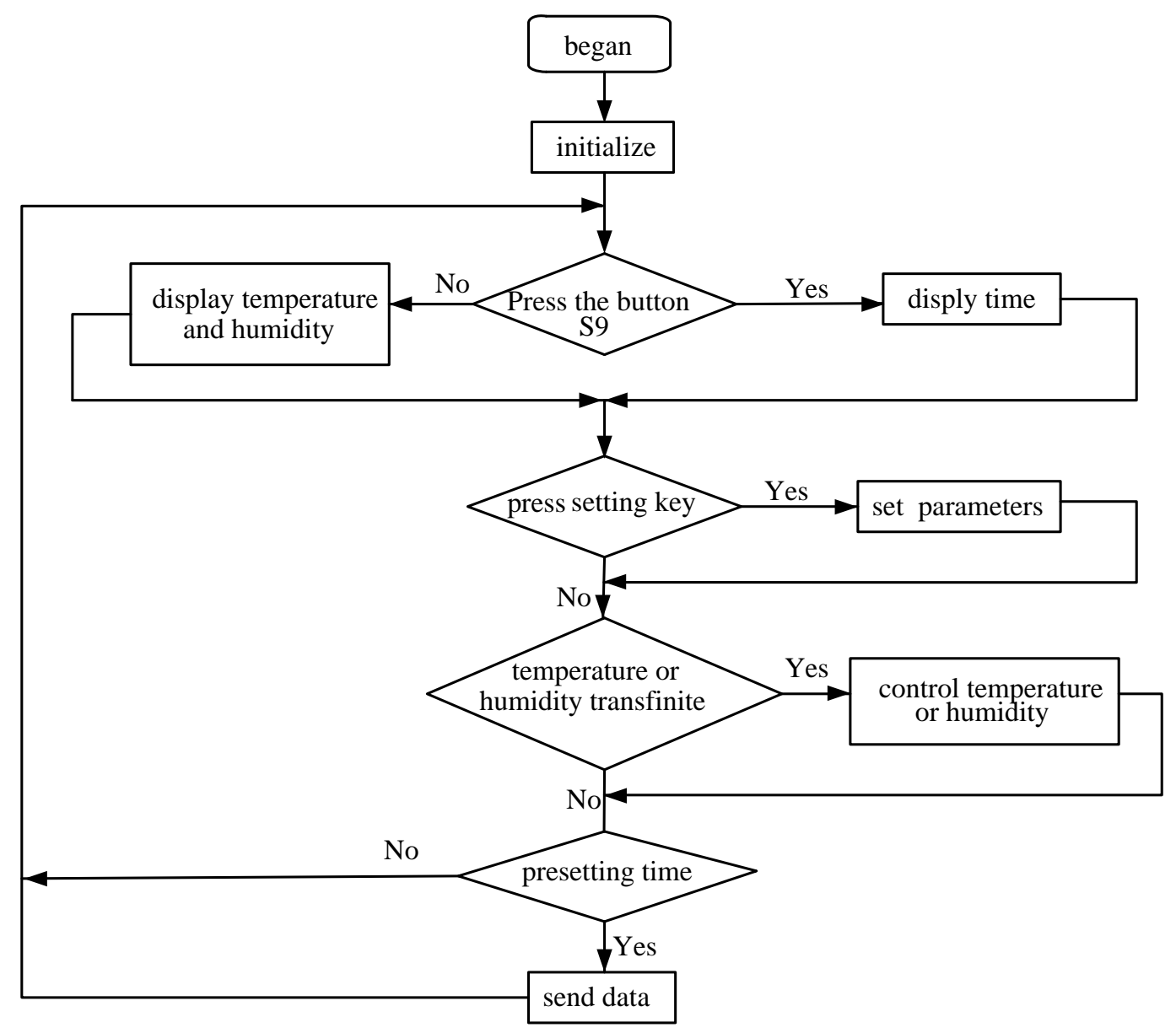

Figure. 4 The main program block diagram 


\section{Summary}

The test results. The system has been tested in a library indoors after commissioning simulated testing, inspecting the control accuracy of the system. Typically air temperature should be controlled between $25 \sim 26^{\circ} \mathrm{C}$ and the relative humidity controlled between $50 \% \sim 65 \%$. Table 1 shows the comparison of the part of the data between the preset temperature and humidity and the measured temperature and humidity in different time of a day. We can see from the above results that the maximum absolute error in temperature is $\pm 1{ }^{\circ} \mathrm{C}$ and the maximum relative error in humidity is $\pm 4 \% \mathrm{RH}$.

\section{Tab 1 Test results}

\begin{tabular}{|l|l|l|l|l|}
\hline Time & $\begin{array}{l}\text { The preset } \\
\text { temperature }\left({ }^{\circ} \mathrm{C}\right)\end{array}$ & $\begin{array}{l}\text { The measured } \\
\text { temperature }\left({ }^{\circ} \mathrm{C}\right)\end{array}$ & $\begin{array}{l}\text { The preset } \\
\text { humidity }(\mathrm{RH})\end{array}$ & $\begin{array}{l}\text { The measured } \\
\text { humidity }(\mathrm{RH})\end{array}$ \\
\hline $8: 00$ & 25.0 & 25.7 & $55 \%$ & $57 \%$ \\
\hline $9: 00$ & 25.0 & 25.9 & $55 \%$ & $54 \%$ \\
\hline $10: 00$ & 25.0 & 25.5 & $55 \%$ & $55 \%$ \\
\hline $11: 00$ & 25.0 & 24.9 & $55 \%$ & $59 \%$ \\
\hline $12: 00$ & 25.0 & 24.6 & $55 \%$ & $54 \%$ \\
\hline $13: 00$ & 25.0 & 25.2 & $55 \%$ & $53 \%$ \\
\hline $14: 00$ & 25.0 & 25.7 & $55 \%$ & $56 \%$ \\
\hline $15: 00$ & 25.0 & 24.2 & $55 \%$ & $56 \%$ \\
\hline $16: 00$ & 25.0 & 25.5 & $55 \%$ & $57 \%$ \\
\hline $17: 00$ & 25.0 & 25.3 & $55 \%$ & $58 \%$ \\
\hline
\end{tabular}

The students' achievement in the project. Through the "national university student innovation and entrepreneurship training program" project, students have learned how to use the knowledge they have learned to solve the problems encountered in practice. In addition, the program improve students' abilities to analyze and solve problems, enhance students' awareness of innovation and solidarity , training students to work independently and rigorously and lay a good foundation for students to work in the future.

\section{Acknowledgements}

The authors would like to express their gratitude to the help of the students' scientific research training program of Xi'an Shiyou University. Thanks are also to all colleagues who previously provide technical support.

\section{References}

[1] Information on http://www.moe.gov.cn/publicfiles/business/htmlfiles/moe/s5972/201404/xxgk _166881.html.

[2] Wang Hailiang, Ren quanchang, Yu Yang,Song Hao, The implementation experience of National college students innovative entrepreneurial training program, China Electric Power Education.25(2013)206-207.

[3] Wang Xi-jin, Successful Graduates as a Model for College Students'Enterprise and Undertaking, JOURNAL OF NINGBO UNIVERSITY. 3(2012)95-97. 
[4] Kisenwether, Elizabeth C.Matson, Jack V.Launching an undergraduate engineering entrepreneurship program, ASEE Annual Conference Proceedings.2002, pp 8599-8606.

[5] Li Shijiao,The construction of college students' innovative undertaking education system, Heilongjiang Researches on Higher Education.209(2011) 119-122.

[6] LIU Chang-hong, LI Xiao-hui, LI Gang, YUE Qing-rong, Ren Yong-gong, Practice and Exploration of the Undergraduate Innovation and EntrepreneurshipTraining Program, RESEARCH AND EXPLORATION IN LABORATORY.5(2014)163-166.

[7] Raviv, Danie1, Teaching innovative thinking: Future directions, ASEE Annual Conference and Exposition, Conference Proceedings, 2009.

[8] QianXiaoming, Rong Huawei, Qian Jingzhu, Practice and thinking of education of College Atudents Innovative and Entreprepreneurial Training Program based on tutor system, Experimental Technology and Management.7(2014)21-24.

[9] Xu Fang-yuan, Wu Lai-ming, Xie Yu-lin, Study on temperature and humidity in the museum environment,SCIENCES OF CONSERATION AND ARCHAEOLOGY.22(2012)53-55.

[10] Lei Caixia,The theory of grain mildew and prevention,Sichuan grain and oil science.4(2003),20-22.

[11] Han Yun, Li Cheng;Zhang Yuan, Liu Dejian, Cao Haijun, Research on moisture control and conditioning of rice in storage and processing, Cereal \& Food Industry.

4(2014)56-59.

[12] Liu, Chenggang, Bruner Jr., Homer L.The optimization of temperature and relative humidity control in cushing library, Advanced Materials Research.v250-253(2011) pp 3139-3143.

[13] Feng Simin,Luo, Zisheng, Shao Shiqi,Wu Binbin; Ying, Tiejin, Effect of relative humidity and temperature on absorption kinetics of two types of oxygen scavengers for food, International Journal of Food Science and Technology. 48, 7(2013), 1390-1395packaged. 